\title{
Exploring the Paradigmatic Thinking and Representation in R. E. Obeng's Eighteenpence: Beyond Plot
}

\author{
Casimir Adjoe \\ Department of Communication Studies and Languages, Faculty of Arts and Social Sciences, Central University, Tema, Ghana \\ Email address: \\ casimir.adjoe@gmail.com

\section{To cite this article:} \\ Casimir Adjoe. Exploring the Paradigmatic Thinking and Representation in R. E. Obeng's Eighteenpence: Beyond Plot. English Language, \\ Literature \& Culture. Vol. 4, No. 3, 2019, pp. 61-69. doi: 10.11648/j.ellc.20190403.11
}

Received: May 22, 2019; Accepted: July 10, 2019; Published: July 23, 2019

\begin{abstract}
When narratives are mentioned, the first thing that springs to mind is plot. Plot is important because of its reference to development and process, which make possible the outlining and enacting of the forms of life that shape up around a particular time and structure. Meaning-making in a narrative is generally dependent on this arrangement and the forms of life it creates from it. Nonetheless, in producing meaning, plot is not the only way of designing a narrative. One other significant way of structuring or designing narratives and creating meaning in narratives is through a pattern: juxtapositioning, parallelism and contrasts. In these meaning making processes of either plot or pattern, time is significant. Plot depends upon a linear sequential process implicating process and development and therefore a beginning, a middle and an end, or time in progression, whereas pattern depends upon time that is held static in a paradigmatic structure of an eternal present, conflating past, present and future. Pattern can occur at the level of words, but also at the level of phrases and sentences (stylistics), or at the level of scenes, chapters, and in parts or divisions. The most essential thing to recognize about all this, however, is that the pursuit and crucial aspect of a narrative is that it seeks to create its own world through the process of packaging what it is creating through a design. The underlying principle of this packaging is 'tying together'. Hence narratives tie together people, objects and facts. And they tie them together in a manner that is stylistically and grammatically acceptable. By tying together objects and facts, and tying people together, and by doing so through stylistic and grammatical means, the argument of the narrative is conveyed at a more implicit level than through an explicit level such as for plot; that is, through the very textual organization of accounts. Using R. E. Obeng's Eighteenpence as example, this paper investigates the significance and effectiveness of creating consequence and meaning through the design patterns of juxtapositioning, parallelism and contrast for narratives which foreground the textual and structural organization of accounts to convey their meaning and arguments. Obeng's Eighteenpence is the first full-length Ghanaian novel (1967), preceding Ayi Kwei Armah's The Beautiful Ones Are Not Yet Born (1968).
\end{abstract}

Keywords: Contrasts, Beyond Plot, Enlightenment Frameworks, Paradigmatic Thinking and Representation, Pattern, Romantic Frameworks

\section{Introduction}

The aim of this paper is to articulate and highlight a complementary way of understanding and making meaning of West African novels, particularly novels such as R. E. Obeng's Eighteenpence, that do not seem to have completely discernible plots, and which are therefore described by some scholars as either folktales or fairy tales. It will hence examine plot and explore its relationship with pattern and design, and describe their complementary roles in making meaning in a novel, depending on which aspect of meaning making is emphasized or highlighted in relation to the author's designs.

While attention and emphasis have generally been on plot in critiquing novels, the resources of meaning production through patterns are given less attention, particularly for understanding narratives and the discourses and arguments they pose. The consequence is that narratives which otherwise enact or construct valuable meaning-making models for both past and contemporary society are being lost. In our African context, narratives that are not specifically built on clearly defined and recognized patterns of plot can 
easily be dismissed as of little value because they do not meet the supposed standards defined for the construction of meaning through plot as a cause and effect sequence. For example, R. E. Obeng's Eighteenpence, has been consistently overlooked by notable African literary scholars perhaps because of its lack of a clearly defined plot, and thus relegated as a 'folktale', as Angmor (1996) observes [1].

\section{Plot in Eighteenpence}

Porter Abbot (2007) in his attempt to establish the connections between the various aspects of narrative points out and distinguishes three different aspects of prose fiction: story, plot, and narration. A story has a separate existence outside the manner it is narrated. The way in which a story is narrated makes it different, giving it diversity or a different form. That is, "the narration of this story would be different, with different words, different emotional inflections, different perspectives, and different details. These narrators might even contradict each other.' [2]. Herman (2007) similarly points out the different turns and diversity a narrative could assume due to the same factors accounted for by Abbott [3]. In a similar way, a story is different from its plot. A story can be plotted in different ways just as it can be narrated in different ways. It is these three components - story, plot, and narration - that constitute what is referred to as narrative. A narrative must have a beginning, a middle, and an end, and it must be composed of action (an event or events) and characters or existents and entities, and it should proceed forward in time $[2,3]$. Hence the common definition of plot refers to and describes whatever happens in a narrative. In this regard, plot is understood to be built of significant events in a given story, and these events are considered significant because they have important consequences. Consequently, plot is created by the way incidents are weighted and presented and converted to events on account of what the incidents lead to, that is, the way in which they are narrated (narration). In this sense, incidents are created into a cause that has significant effects. The resultant product is a consequence of cause and effect. Hence plot can be described as a product of cause and effect [4]. For instance, in R. E. Obeng's Eighteenpence, the plot develops from the incidents in the life of one man, Akrofi, described as 'as poor as a church rat' (p. 1), and his desire to 'ascend to that rung in life in which one is expected to be happy and merry - marriage' (p. 1) [5]. The gap left between being too poor, and the aspiration to achieve happiness through marriage produces many incidents which could be weighted in terms of their value and importance, and the effects each incident produces culminates in causing other outcomes and resultant actions, enabling the movement of actions, structuring the entire experience into a clearly defined movement from a beginning to a middle and to an end. When circumscribed within this continuum, plot can be said to consist of the things characters do, feel, think, or say, that make a difference to what comes afterwards. [4]

The main challenge, however, is how a plot convinces its reader that whatever is happening matters intensely. This produces the first potential for creating plots with outer and inner sides which in some sense mirror and reinforce, or conflict and contrast (with) each other through actions recognized as scenes. A scene is a setting/incident/event connected with sequential actions, together with its embedded description and background material. A scene seems to happen just as if a reader were watching and listening to it happen, as it is built on talk and action. It also has the characteristic of being dramatized; that is, it is shown rather than being summarized or talked about. In some ways, it resembles an independent story. However, a scene arises for a reason, and it has direction like a set piece. It has meaning, making a point about at least one thing that needs to be shown or established at that spot in a story. Consequently, as an example, even an attitude can turn into a motive, meet resistance, create conflict, and lead to consequences, leading to becoming the plot for a scene or for the entire narrative. And so a scene can convey many good things: moods, attitudes, a sense of place and time, an anticipation of what is to come, a reflection of what is past. But above all, the raison d'etre for a scene is to move the plot forward and demonstrate the characters. Creating scenes, therefore, also means finding the ways by which a story can show itself rather than merely telling it. This property of the narrative concerning the scene at the same time creates the space for the emergence of paradigms, patterns or designs in the manner they are being tied together in the plot through juxtapositioning, contrasts, echoes, and parallelisms.

However, as plot can be described as a product of cause and effect, thought or emotion becomes part of plot only when it becomes action and causes reactions. "Until then, attitudes, however interesting in themselves, remain just potential and cloudy possibilities." [4] Emotions, attitudes and thoughts and happenings which are unable to produce cause and effect sequences because they cannot become actions and cause reactions are classified as static, no matter how dramatic they may seem. On the other hand, any actions, no matter how trivial they may seem can be vital and memorable if they manage to create or enable significant consequences to the outcome of the story. For this reason also, Dibell (1990) proposes that using plot can be seen as a way of looking at things since "It's a way of deciding what's important and then showing it to be important through the way you construct and connect the major events of your story. It's the way you show things mattering" [4].

In effect, the interest in a plot arises mainly because of what is at stake, that is, what is of value to be gained, or of value that can be lost because of the manifestation of an emotion, attitude, thought or action. In effect, it is a description of why it matters at all that things are considered in a particular way, hence what it means for the survival or otherwise of the characters. For Dibell (1990, p. 7), it is this very aspect of risk in plot that elevates it beyond what is ordinarily referred to as a 'theme', a 'message' or a 'topic'. Dibell (1990) also borrows from Paul Boles' (1984) term to focus attention on a conceptualization of the action of plot 
and notes that this characteristic of plot should better be represented as 'wrestling' [6]. What the use of the term 'wrestling' achieves by its reference is a projection of the importance of something specific happening. It outlines a struggle due to complications or entanglements such as two strong opposing or conflicting forces meeting in which one of them has to triumph over the other. As Boles (1984) notes, this triumphing may happen for better or for worse. In such a case, the forces may be external to the main character (the protagonist) such as a villain, an opponent, a set of circumstances, a feature of the environment or of the landscape [6]. On the other hand, both forces may dwell within the protagonist, as for instance in the fear of doing something or wrestling with the need to do it or a sense of injury or wrestling with love or admiration etc. (Dibell 1990, p. 7). In Eighteenpence, this 'wrestling' or conflict is set up as external forces between Konaduwa and her community. Subsequently, when Konaduwa is defeated and silenced and retired into marriage by her community, her role is taken up by Akrofi who now assumes the role of protagonist, and the struggle takes on or adopts a parallel but different style and mode that sets, impels and thrusts him on a series of triumphs over the chiefs and the community and their attempts to customize and de-individuate him, using the court system which sets up a juxtaposition between, as Dako (1999) observes, the traditional and European legal systems, and Newell (2000) points out, becomes meaningful as an exploration of the preoccupations about marriage, manhood and money by the population against the chiefs and the manner in which they employ these to control the community and individuals [7, 8]. Akrofi launched his attack and achieved his total triumph over the chiefs by winning a case on property right contested against the chiefs in a European style court, setting him up to attain individual freedom and thus assume total control over his own life and environment, and enable him to establish a European style estate and engage in local philanthropic work as an individual or 'singular member' of society rather than a 'social by nature' individual.

The second part of the narrative, (chh 13-19), began with what was at stake for Akrofi - the desire to adopt a different approach to farming and increasing his harvest and wealth by adopting European methods of farming. The opposition was both external and internal (psychological) - the ridicule of the traditional community, including his friends who considered him as mad because he cultivated his crops, not according to the 'rule of thumb' method, but by digging the ground and raising beds for the crops, planting short hedges between various sections of the farm and crops and creating and measuring distances between the crops, controlling the weeds and insects on the farm, which his contemporaries regarded as 'wasting time and strength and money' (p. 83) [5]. He kept his farm very tidy, 'and as it was not far from the town, many people walked there to see it for amusement.' (p. 84) [5]. The challenge to his new approach and mentality to farming intensified even as his European style farming yielded rich harvest and wealth. Instead of convincing members of the traditional community to follow his example or to learn from him, they grew more adamant towards him: 'People began to think that he had some supernatural power with which he worked, because he reaped everything in much more abundance than any other farmer whose farm was about three or four times larger than Akrofi's. Any explanation he gave them was rejected; but he thought the people were simple-minded and that was why they could not understand; for it was a waste of time trying to make them see why such a small farm could yield such abundance.' ( $p$. 85). ... Nobody understood what he was doing. They laughed and derided him as usual; but he was resolute like a rock.' (p. 89). [5]

In as much as his farming methods were rational and wellordered, Akrofi also selected a wife by a rational process of assessing each girl's behaviour and mode of speech rather than by any process of kinship relationship or traditional processes of wife-selection.

Thus, what is at stake produces 'wrestling', that is, the struggle for individual freedom against the desires of the traditional community, and the plot has to convince its reader that whatever is happening matters intensely. What mattered for Konaduwa was expressed by Dako (1994) as a desire to be a respected individual in the community who would be heard on the merit of her truths, and not based on her biological and ascribed social status as a woman; and for Akrofi, on the other hand, what mattered was the desire to be an individual with the freedom to own property and to develop his entrepreneurial capacities to the fullest in order to produce wealth. But he was determined to achieve this without the interference from the community's disincentives of rivalry, rumour-mongering, incessant litigations and timewasting traditional court sessions which eventually only result in the usurpation of the individual's wealth, time and energy by the chiefs and the community. A significant outcome of this quality of 'wrestling' is that it provides the capacity for a plot to create sequences capable of bearing what Dibell (1990) refers to as an outer and an inner side comparative parallelism that enacts paradigms. These outer and inner sides of plots provide them with another quality, which is the potential for creating a mirror or parallel sequences in order to reinforce, or to implicitly conflict and contrast with each other in order to produce struggle. In such an instance, neither the outer plot nor the inner plot works alone to produce meaning. An integrated meaning can be produced only when the focus of interpretation or meaning making is centred also on the inevitable struggle mirrored in the actions occurring in the scenes or sequences of the actions of the plot. This aspect of plot, producing an outer and inner side in order to provide a mirror of the plot, or on the other hand, to contrast it, occurs in R. E. Obeng's Eighteenpence, such that the book is divided into two parts, (chh 1-12 and chh 13-19), with one part mirroring and contrasting the other, suggesting that the novel is not simply about events, but about important principles at stake, an argument comparing or reconciling two conflicts and drawing a conclusion concerning a struggle of individuals 
attempting to come to terms with a static, suffocating and demanding social environment. In this regard, the arrangement of plot into an inner and outer side creates a kind of juxtaposition resulting in the production of comparisons and contrasts. They succeed as mirrors of each other because both sides of the plot are compared as static entities. As this paper will explain later, juxtaposition is most effective as a tool for harnessing the static pieces within a narrative for analysis and meaning making in comparison and contrast with other pieces in the story. In this sense, both parts of the novel act as separate paradigms. Each paradigm is circumscribed by its own plot, but each is in turn constituted into a paradigm.

Another significant element related to what is at stake in the plot for the composition of a narrative that Dibell (1990), and also Herman (2007), point out is that a story needs to be founded on an effective and strongly-felt conflict or 'disruption' (Herman 2007) in which the opposing forces, be they people, ideas, attitudes, or a mix of these, are at least fairly evenly matched to the extent that the final outcome is in doubt. [4, 3] And to create drama and suspense, the forces opposing the protagonist could even seem slightly the stronger. The danger here though, is that, if not carefully handled, a mismatch of opposing forces can be created, which can defeat the raison d'etre of a plot; for, in all, it is the struggle or wrestling that is most important in creating involvement in the narrative and that governs the sequence of narrative rather than the outcome of the struggle itself. In Obeng's Eighteenpence, Konaduwa, the protagonist of the first part of the novel, presents herself as a strong force capable of opposing the society by opposing its institutional symbols (chiefs, husband, mother-in-law, rivals, the district commissioner, etc), positing and presuming with various utterances that she was as strong as any man, or even stronger than all the Abetifi men. Her orientation and posture can be summarized in the outcome of one of her numerous confrontations with her husband, Ademueri. At one time, Ademueri, while reporting how Konaduwa had overpowered him, pointed out to his second wife, 'Look at my cloth. Konaduwa has torn it to pieces. Look at my forehead, which struck against the frame of her door when she pulled me down, the place has swollen.' (p. 9) [5]. Ironically, instead of being thought of as a strong force as she supposed, she was rather dismissed as 'Konaduwa was not in her right mind.' (p. 9) [5]. The novel, therefore, implicitly, demonstrates and displays her as an unequal force, although in her own estimation and imagination, she could take on the society, including the chiefs, and boasted that she was stronger than the men in the villages and towns. In the end, as Dako (1994, 1999) observe, she discovers her powerlessness against the status quo of a society or community which has been so structured upon a romantic paradigm that it was almost unassailable for an individual to take on. [8, 9]. Consequently, she was run down through a system of numerous traditional court sessions which consumed her time, energy, and resources. Being incapable of sustaining so many numerous court cases of which she lost all, and whose fines other people had to bear on her behalf, she could not afford to continue incessantly to challenge a community she had too little resources to withstand. Her eventual humiliation and re-embedment in the community was as a 'social by nature' being and not an individual capable of separating herself from it, as is summarized in Chapter 6:

After the sheep had been slaughtered and the announcement made to the Adontenhene and his Elders, Anyinam returned to arrest Konaduwa as a prisoner of oath. She was asked to pay the arrest fee of eight shillings; but as she had no money on her, she gave the silver bangle she wore on her left wrist in lieu of the amount. A piece of hollowed pawpaw stem was given to her as a sign of her being a prisoner of oath. This she was ordered to carry with her anywhere she went until the case would be heard and judged. Formerly, the wrist of an oath prisoner was shackled to a heavy log; but when the conditions were ameliorated by the advent of the white man, a hollow pawpaw stem was issued instead. When the prisoner was brought to court, she was asked to find someone to stand surety for her. She asked her husband to do so. Owusu said he could not do so without any of her relatives. Her maternal uncle and her father came to support Owusu. They were asked to swear that in the event of Konaduwa losing the case, they would readily pay all the expenses without trouble or delay. They swore to do so.' [5]

In sum, Konaduwa and Akrofi, although not allies in terms of the conscious composition of a group with a focus on challenging society, are nevertheless allies in their common determination of what is at stake for the preservation of their individuality and in choosing deliberately to confront the status quo of the community although by different methods, mirroring each other in this regard through a parallelism. In the end, although silenced through marriage, Konaduwa had opened a path for Akrofi to use his mind, and to raise his own consciousness in order to question the systems of the community that nearly made his life a misery. Such an orientation of mind was what Konaduwa had attempted to stir in Akrofi when she challenged him in the farm at the beginning of the book by asking him Socratic questions regarding his indentureship to Owusu Ademueri thereby setting off the whole chain of events in the narrative. Hence, although contrasting in several regards, Konaduwa and Akrofi ironically converge in their composition of a force engaged in a struggle against the deadening effects of the community and its value system. Thus, whereas at the domestic level, Owusu Ademueri, the husband of Konaduwa represented a slave-owner, although reluctantly, by owning an indentured worker, he can be compared at the societal and community level to the chiefs who 'owned' the people in the community as indentured workers whether they knew it or not by the emphasis of the kind of authority they wielded over the community and the individuals in it, and the intolerance of dissent in the community.

Eventually, effective plots are made on the basis of struggle, conflict, dissatisfaction, aspiration, and choice and the like the existence of a gap that needs to be overcome. Dibell (1990) posits that the challenge of determining what ideas can conduct 
a writer towards realizing the basic ingredients of a plot also leads to asking four basic questions: [4]

i. What the author really cares about; in other words, something that the writer partly understands and feels needs working out.

ii. Whether what the author cares about is so relevant and meaningful, not only to the writer but also to readers such that they can feel like involving themselves in it because of what is at stake in the story.

iii. Whether the idea can be carried forward by tying together people, ideas, places, things, and emotions and attitudes, and being dramatized to produce a series of scenes resulting in cause and effect follow ups with a minimum of explanation.

iv. Whether the author can show how what is at stake or causing the wrestling, conflict or struggle is so important to the main character/s that the reader can be made to understand, empathize, and care about what happens to them.

Eighteenpence appears to answer all these questions except the third question where the showing and dramatization of scenes, although present, do not offer the sense of an arrangement into a normal plot series of cause and effect. Instead, these dramatic scenes appear to be pieces of mosaic representations (paintings) of scenes that bring together meaning and interpretation by a different means than cause and effect sequences. Their means of bringing meaning to bear in the novel is by juxtapositioning, design and paradigm or pattern. Consequently, the composition of the story of Eighteenpence cannot be regarded as a plot in the traditional sense. Its composition goes beyond plot (Dibell 1990). This quality of Eighteenpence going beyond plot to create meaning in a story will be explored below through structure, pattern or paradigm.

\section{Paradigmatic Thinking and Representation in Eighteenpence and the Shape of the Story: The Kind of Story the Writer Is Telling}

Neusner and Chilton (1997), in examining the characteristics of paradigm, and distinguishing it from plot sequences describe it as explaining the pattern of events: in effect, making connections, and drawing conclusions. Thus, "paradigmatic thinking, no less than historical, explains matters; but the explanation derives from the character of the pattern, rather than the order of events, which governs historical explanation." [10].

The character of the patterns that make explanation possible in turn depend upon the connections drawn between one thing and another but not on temporal sequences. In this regard, Neusner and Chilton (1997) emphasize the principles of selection, the kinds of connections made through these selections to draw conclusions, and the rich instantiations of such articulations as the driving force behind the explanatory power of paradigmatic sets.
Thus, in paradigmatic or pattern thinking, selection of objects, things, moods, scenes, events et cetera, and the types of connections drawn between one thing and another, and the rich examples of these in a narrative are key to any explanations or meaning-making and significance determined of a text or narration.

For example, the creation of a narrative text does not only depend on actions, attitudes, and thoughts, but also on the choice of words, dialogue, style, tone, and point of view in order to tie together people, ideas, and facts. For this reason, the manner in which characters and situations and events are invented or depicted, depend largely on how they are meant to be tied together. A narrative thus comprises the construction of scenes, the ordering of events, designing the complications and twists, and the setting and the historical background. It is the end product of this process or the composition that makes a 'storyteller'. In this process, inventing a character for a composition also depends on a writer's sense of what is important and true, because that is what helps to make a writer's decisions. Making such decisions about what is important and true is crucial because it influences the creation of different types of characterization and different types of plot and fiction.

This leads to different types of story, which emerge based on four different factors that can be identified. These four basic factors are, nevertheless, not exclusive, but rather present in every story with varying degrees of emphasis. The fashion in which these factors are balanced and blended in the story determines what sort of characterization and flavour a story must have, should have, or can have. Following Dibell (1990), for example, the four factors involved in the blending determining the flavour and type of story possible include the following: milieu, idea, character, and event [4]. The milieu defines and describes the world surrounding the characters, including the landscape, the interior spaces, and the surrounding cultures from which the characters emerge and which they react to, including everything from weather to societal practices. The idea engenders the crucial information or philosophical outlook that the reader is meant to discover or learn during the process of the story. Character points to the nature of one or more of the people in the story, that is, what they do and why they do it the way they choose to do it or are obligated to do it. And so character usually leads to or arises from a conclusion about human nature in general. Events of the story point to everything that happens and why they happen at all.

These factors do not stand in isolation, of course, and usually overlap with each other, or one with the other. For example, the character, Konaduwa is part of the milieu surrounding the character, Akrofi. The idea in the story may include information about the nature of a character; and the idea we are meant to discover can be some aspect of the milieu, some previously misunderstood or overlooked event, or the nature of a character. The events of the story are usually performed by characters or emerge from the milieu, and the discovery of an idea can also be an event in the tale. Consequently, each factor is present in all stories in one 
degree or another. Every factor, though, exists with its own implicit structure. If that factor and its structure dominate or foreground a story, that implicit structure determines the overall shape of the story. That is the reason, although all the four factors are present in Obeng's Eighteenpence, the predominant and foregrounding structure giving an implicit framing to the novel is its setting or milieu factor. It is this milieu or setting and its structure that shape the focus and nature of the novel. By implication, it is dealing with a state of being, which is by nature static and from which an idea will emerge. Nonetheless, the author will seek to give the impression of movement in the milieu by adopting the method of pattern or structure which utilizes the techniques of juxtapositioning or mirroring, echoes, or parallelisms and recurrences and contrasts to describe and connect scenes, incidents, attitudes, decisions and choices, and others related to tying people, things and ideas together in the story.

Also, a narrative always makes implicit fictional promises to the reader at the beginning. Narratives that use pattern or paradigm are conscious of these promises. The manner in which these implicit promises are fulfilled later on is through mirroring, parallelisms or juxtapositioning. These are developed and reinforced through instantiations of recurrences and echoes. It is when discovering these promises through the scenes that mirror, parallel, contrast or juxtapose them with others and how they are developed, and why they are so constructed that the power that lies beyond plot is revealed or discovered - the power of pattern. The promises that the author makes to the reader in Eighteenpence appear at the very beginning in the first two paragraphs of the story: Akrofi is a poor man, and yet he had aspirations, and he will struggle against poverty in order to achieve his aspirations; and what kind of struggle it will be, how it will be carried out, what the opposition or the challenge will be, and what its outcome will be, constitute the story's events. Thus:

'In the ancient and salubrious town of Abetifi, in the country of Kwahu, in the reign of Nana Addo Kese Pamboo, there lived a man whose name was Obeng-Akrofi. Obeng, though kind-hearted, was as poor as a church rat. He was also so self-conscious that he could not approach any of his friends or relatives for anything. His property on earth, besides his only cloth which was threadbare, was a small dog who followed him anywhere he went. This dog he named 'Poor-no-Friend'.

Akrofi wanted to ascend to that rung in life in which one is expected to be happy and merry - marriage. As this step cannot be taken in any country without spending of much money, Akrofi was likely to be embarrassed. This prospect of embarrassment goaded him to go to .....' [5].

Characters must have a place in which to perform the actions that make up the story, thus, the setting or the milieu of the story. The milieu includes the instantiation of all the physical locations that are used - towns or cities, houses or buildings, a chief's palace, a village square, a street, a farm, a clearing in the woods, a shop together with all the sights, smells, and sounds that come with the territory. The setting or milieu also includes the instantiation of culture, such as the customs, laws, social roles, and public expectations that limit and illuminate all that a character thinks and feels and says and does.

In some stories, the milieu is very sketchy; in others, it is created in detail and is the primary focus of attention such as the scenes of quarrelling, arbitration and court sessions which are given detailed attention in Eighteenpence. Through the perspective of Dibell (1990), it can be understood that the concern of such stories is not to explore the soul of a character or to resolve a tense and thrilling plot, but rather to set up an argument and explore a world that is different from our own world, is set in a different time, or has a different way of seeing things, comparing it to our own customs and expectations. Thus it is that the author of Eighteenpence explores the society of his time through the creation of this kind of storyworld [4].

One characteristic often found in stories where the milieu is dominant is that the structure is made simple, and characters are put in a specific or suitable setting and a reason is devised for them to move through the world of the story, linking the reader to all the interesting physical and social details of the milieu. After the reader is shown everything that the author wants him or her to see, the character is retired. This is what happens in the first plotline of Eighteenpence in which, through the character of Konaduwa, we are led to see the workings of the social situation of the novel in which Akrofi pawns himself to work for Owusu Ademueri, Konaduwa's husband, until he has paid off a debt of eighteenpence. It is elaborated through the instantiations of anger, quarrelling, nit-picking, excessive court sessions, slaughtering of sheep, swearing of oaths to fetishes, numerous fines, long hours of sitting by chiefs and people to judge petty quarrels occasioned by domestic jealousy and so on, and the love for ornaments and adornments and the display of chiefs and their ranks through such adornments and ornamentation which are rife in the narrative. Its overall sense is one of a milieu replete with social control (Dako and Yitah 2012), equivalent to suffocation as exemplified in Akrofi's pawning of the self the whole milieu as a mirroring of the first scene of enslavement in which Akrofi pawns himself because he has no other options by which to survive and to achieve some status in life in order to be recognized as a human being [11].

Also, in most predominantly milieu stories, the main character is not heavily characterized and hence not made an individual as such; instead, the main character is characterized sketchily and given a semblance of a representative figure of everyman or woman. This is so because if the character is too individualized, it will draw the readers' attention to him/her and away from the milieu. Hence the author wants to keep the readers' attention instead on the milieu, and the main character's reactions to everything that happens is made as 'normal' as possible. In such regard the characters are not chosen for their intrinsic interest, but because they also typify certain kinds or classes of people within the culture. The characters are meant to 
fascinate us, not because we necessarily understand them or share their desires, but because of their strangeness, and what they can teach us about an alien culture, such as we glean from Konaduwa as a character in the novel.

In such milieu stories the author also feels free to digress from the main story line with long passages of explanations, descriptions, or depictions of the culture. As such, in a milieu story, characters do not need much characterization since most characters need only be stereotypes within the culture of the milieu, acting out exactly the role expected of them in their society, with perhaps a few eccentricities that help move the story along.

The fact is that when a story spends time on a character, an event, a question, or a setting, the reader expects that the main thread of the story will somehow be affected by it. Eighteenpence, by its structure, points to the setting as the primary interest to the author and hence the factor that dominates and frames it; and stories with an interest in setting are most conducive for the use of pattern or design for structuring meaning because they tend to be more stable and unchanging, considering things such as environment, culture, and people. Scholes (1968) describes that in such a situation or context, the author adopts a style that gives the impression or illusion of movement, because movement helps to avoid creating boredom and lack of interest in a static life and objects [12].

In keeping the unspoken promises of the story to the reader, mainly in unspoken ways, pattern is also most conducive because it connects things, people, ideas and events mainly through the techniques of emotional resonances or echoes and mirrors. And so, although the individual situations or scenes in a story may be vastly different from one part to another, once the emotional resonances of these seemingly different scenes are similar or contrast within the same continuum, the manner of heightening the echoes and mirrors enables the reader to see how the scenes are linked.

Scholes (1968) refers to this kind of structuring of narratives through juxtaposition and repetition as design. "Yet design is an important part of the writer's art, and a sense of design is essential to a full reading experience." ([12]. Design or pattern in fiction take many forms, and Scholes (1968) identified these forms as mainly of two kinds. One has to do with juxtaposition: with what is put next to what, referring to the arrangements within the story. The other has to do with repetition: with how images, ideas, or situations are repeated, often with interesting variations, in the course of the narrative. Juxtaposition is more important in some kinds of fiction than in others. A single action can be presented in a simple, chronological arrangement. In this regard the order of events is not likely to assume any special significance. But when the action, is rearranged in time so that events are encountered out of their chronological sequence such as through flashbacks, flash-forwards or some other device significance is created. In this case the order invites attention because it may be indicating an important message. It means we must look for reasons behind this manipulation of chronology by the author. For example, why has he chosen to place this particular scene from the 'past' next to this particular scene in the 'present'? In the same way, if we are following two actions in one story, now one and now the other, we should look for reasons why an incident from one sequence should be placed next to a particular incident, and in that order. This may lead us to interesting parallels, which are similar situations that amount to a kind of repetition with variation. Thus, one character may get into a situation and take one kind of action while another character, in a similar situation, may take a different action; we should be able to compare the two and contrast their distinctive behaviours. This may provide an opportunity to learn more about both. This kind of repetition is an important element of design, and serves to tie separate parts of a story together, enriching and strengthening the whole structure.

Consequently, Scholes (1968) explains that structure in fiction is a very complicated notion because it involves many factors. Nonetheless, one valuable sense too in which we can think of structure is as those elements which shape our experience as we move from one place to another through the story. In this sense structure comes close to plot. On the other hand, we can also think of structure as those elements which enable us to see a meaningful pattern in the whole work. And it is in this sense that structure is close to design. Both notions interact and merge, though. Plot has to do with the dynamics of movement in fiction and the way we see a whole story after we have stopped moving through it; on the other hand, we become aware of design in reading when one part of a story reminds us of parts we have read earlier, and this involves a movement counter to our progress in the form of moving through from beginning to end. Consequently, in a sense, plot pushes us along, whereas design wants to delay our movement (s) in order to make us pause and 'see'. This produces something like a counteraction. However, the counteraction of these two forces is enriching, and is one of the things which enriches our reading and experience of fiction. Ultimately, structure or design produces recurrences, and is thereby often a matter of the repetition of images or metaphors.

\section{Conclusion: Patterns, Mirrors, and Echoes}

By writing, the author chooses what happens and what doesn't, and what is possible in the world of the story and what is not. What characters are concerned about is related to this fact because it becomes the story's concern as well. The kinds of people the author selects as characters, their attitudes and capacities, and the kind of relationships given to them and the kind of connections they have with other characters, with things, moods, events, places, time, and others are all going to add up to a pattern.

The accumulation of details of incidents and of characters shape the form or pattern of the story, creating its implicit rules and realities. It is the pattern that holds the story 
together, but remains unconscious until articulated by the reader's mind, and it is the implicit rules and realities of this pattern that give it both diversity and unity.

Patterns happen in stories all the time, but the problem is about recognizing the patterns as they accumulate, occur, and are strengthened through making them coherent and through clarifying their aspects and direction, and by recognizing the deliberate patterns created through the subtle power of recurrence that creates the unconscious meanings through the echoes established through recurrence. The writer produces these effects deliberately, to a large extent because of the way they want their technique to work as Orson (1995) alerts the reader: "The kinds of repetition that work in fiction, that make buried but not-quite-hidden connections that can hold a story together, aren't a matter of single words. They're part of a writer's larger vocabulary: image, incident, situation, character." [13].

Thus, in order to reach the kind of meaning-making possible through pattern or design, a reader should depart from the habit of thinking in terms of things or isolated and individualized entities and think instead in terms of the categories of things. Thinking in terms of the categories of things enables the reader to see more resemblances, echoes, and outright repetitions in a narrative than one would have ever suspected. Thinking through categories rather than individual or isolated pieces reveals the family resemblances embedded in a story. As asserted by Barry (2000); Scholes (1968); Dibell (1990); Orson (1995), these as much compose an author's characteristic concerns through which he creates the internal riveting of the narrative to produce the echoes directing the reader to a single guiding consciousness [14]. In this kind of style, a scene at the beginning of a story can mirror another scene at the end, and an image in one of the parallel plotlines is mirrored in the same image in another plot. In the interpretation of such stories, therefore, noticing the patterns of the initial scenes and set-pieces usually set up echoes which are reinforced in other scenes. Eighteenpence is dominated by this style. In this novel, the basic emotional dynamic is shown in objects, ideas, images and situations which are repeated throughout the rest of the story. These are shown through the repeated patterns of disputes, court sessions, jealousies, insults, and deceptions throughout the story. The story is replete with trials: The arrest and trial of Konaduwa (Chapter 6); The arrest and trial of Owusu Aduemiri (Chapter 8); The trial of Akrofi (Chapter 10); The trial of Abire (Chapter 12); The trial of Akrofi before the District Commissioner (Chapter 16). The pattern created out of the similarities and meaningful differences chapter by chapter echo recurrences of a suffocating milieu of social control and the desperate attempts by two dissimilar characters, one wielding an individualistic or atomic and rational tradition (Akrofi), and the other wielding a romantic or 'social by nature' individual tradition (Konaduwa) to wrestle themselves out of the clutches of a suffocating social control, as Dako (1994, 1999), and Newell (2000, 2002) argue especially in reference to women's rights in Ghanaian traditional and colonial society, into the triumph of freedom, individuality and prosperity predicated by industry and enterprise (Akrofi) and 'gender equality' (Konaduwa). [9, 8, $7,15]$

Alternatively, contrasts are set up from the initial scene and situation in what follows. Setting up pairs of opposites, or the continuum that connects such a pair, is also a kind of connecting, even when it is not repeating the identical pattern. In this way, pattern also creates embodiment as it suffuses composition with emotional resonances. Hence two situations are designed to be connected, they are linked through recurrences by continuing some specific elements of the first situation in the second.

This wise, we read a plot to find out what happened, but repeated readings of the text invite us to see the patterns in the narrative. In this regard, it can be argued that it is the patterns that the incidents and the people make, but not the incidents and the people themselves that give the story its richness as we notice through our reading. Thus, echoing Scholes (1968), patterns may seem abstract at first, compared to crises and characters in plots, but it is the patterns that make the more lasting impression.

\section{Recommendations}

What R. E. Obeng draws attention to in Eighteenpence is the presence of two competing frameworks of thinking in Ghanaian and African society - one romantic (social by nature), and the other enlightenment (individualistic and rational/ singular member) frameworks. These two frameworks that constitute two different paradigms for society depend upon two radically different assumptions. Yet these two frameworks, which have their own consequences and therefore advantages and disadvantages, need to be identified and reckoned with. One of the frameworks, the romantic framework, appears to have predominated in the kind of society Obeng describes, but has inevitably to be confronted with its other, the enlightenment framework. One of the most important things Obeng points out subsequently is that the two systems can co-exist, but this requires a kind of mental capacity that belongs to the person who is able to think like a bi-lingual or multilingual and who perceives in the manner of a bi-lingual or multilingual. The implication is that living in such a society now requires the development of the kind of mental capacity that can see two or more paradigms simultaneously. Such mental capacity will have to be essential to understanding and solving profound conflicts across cultural, religious, philosophical, ideological and other types of differences and different world views and be capable of also developing cross-cultural approaches to problems and conflicts, and to interdisciplinary approaches in solving puzzling challenges in society. Thus, it is possible to hold two or more world views, paradigms or frameworks simultaneously without rejecting or privileging either and be able to work through them objectively to reach their implications based upon the corresponding data available, requiring the suspension of judgement. However, at the same time, for Obeng, matters should not necessarily end at the 
suspension of judgement. In the end, what results from the suspension of judgement should be employing all the paradigms or frameworks available as a resource while learning about what one did not know before, and what one has discovered that they did not know that they did not know. This should be conducive to a choice, of either reconciling the opposites, and if not possible, then of being innovative and courageous enough in selecting the more progressive, not necessarily the natural or the commonly accepted or the status quo. In this vein, the individual must be prepared to swim against the tide even as Akrofi did in choosing the enlightenment approach (individualist and rational) over the romantic approach (social-by-nature). In this regard, the present kind of society that predominates in Ghanaian and African society will need more individuals like Akrofi who would be courageous enough to make decisions and choices that may seem to others rather 'non-conformist'.

\section{References}

[1] Angmor, C. (1996). Contemporary Literature in Ghana 19111978: A Critical Evaluation. Accra: Woeli Publishing Services.

[2] Abbott, P. H. (2007). "Story, Plot, and Narration". In Herman, David (ed.). The Cambridge Companion of Narrative. Cambridge: Cambridge University Press.

[3] Herman, David (ed), 2007, The Cambridge Companion to Narrative, Cambridge: Cambridge University Press.

[4] Dibell, A., Scott Card and Turco. (1990). How to Write a Million: The Complete guide to becoming a successful author. London: Robinson Publishing Ltd.
[5] Dako, K. (Ed.). (1998). R. E. Obeng. Eighteenpence. Accra: Sub-Saharan Publishers.

[6] Boles, P. D. (1984) Storycrafting, Writer's Digest Books.

[7] Newell, S. (2000). Ghanaian Popular Fiction: 'Thrilling Discoveries in Conjugal Life'. Oxford and Ohio: James Currey and Ohio UP.

[8] Dako, K. (1999). Gender roles as indicators of social change in a colonial novel: R. E. Obeng's Eighteenpence as sociohistorical source material. IAS Research Review. New Series Vol 15 nos. 1. 1999: 60-79.

[9] Dako, K. (1994) "R. E. Obeng's Eighteenpence: A Critical Review”. Journal of Black Studies. Vol.

[10] Neusner, J. \& Bruce Chilton (1997). The Intellectual Foundations of Christian and Jewish Discourse: The Philosophy of Religious Argument. London and New York: Routledge.

[11] Dako, K. \& Helen Yitah. (2012). "Pidgin, 'broken' English and othering in Ghanaian literature". Legon Journal of the Humanities: Special Edition of Papers from the SPCL Conference 2011. 202-230.

[12] Scholes, R. (1968). Elements of Fiction. London and Toronto: Oxford University Press.

[13] Orson Scott (1995). How to write a million: The complete guide to becoming a successful author. London: Robinson Publishing Ltd.

[14] Barry, P. (2002). Beginning Theory: An Introduction to Literary and Cultural Theory. Manchester and New York: Manchester University Press.

[15] Newell, S. (2002). Literary Culture in Colonial Ghana. Manchester and Indiana: Manchester UP and Indiana UP. 